\title{
Las ideas estéticas de Marx a la luz de conciencia y realidad en la obra de arte
}

\section{Marx's aesthetic ideas in the light of consciousness and reality in the work of art}

\author{
Luis Guillermo Martínez Gutiérrez \\ Universidad Nacional Autónoma de México, México \\ luisgmomartinez@hotmail.com
}

Resumen: En este artículo, el autor incorpora la tesis de grado de Maestría de Adolfo Sánchez Vázquez, Conciencia y realidad en la obra de arte, para estudiar cómo se da teóricamente el paso del marxismo ortodoxo que sostenía al marxismo crítico o filosofía de la praxis que después postuló. Este estudio pretende ser una primera parte de un intento de sistematizar la totalidad de su pensamiento estético, por lo tanto, se estudian algunas nociones importantes que a lo largo de su vida académica desarrolla.

Palabras clave: marxismo crítico, estética, filosofía de la praxis, filosofía mexicana, Adolfo Sánchez Vázquez.

Abstract: In this article, the author incorporates into the bibliographic catalogue of the philosophy of praxis, the master's degree of Adolfo Sánchez Vázquez, Conciencia y realidad en la obra de arte, to study how he took a theoretical step from orthodox Marxism to critical Marxism or philosophy of praxis. This paper constitutes a first part for making one systematize existing information of his thinking, for this reason some 
important notions and concepts developed along the life of this philosopher are approached.

Keywords: Critical Marxism, Aesthetics, Philosophy of praxis, Mexican philosophy, Adolfo Sánchez Vázquez.

Recibido: 28 de septiembre 2018 Aceptado: 3 de noviembre de 2018 http://dx.doi.org/10.15174/rv.vi25.427

$Y$ ahora ¿qué?

Tristes pétalos de prematuras rosas, temblorosas corolas aturdidas, blandos tallos de tréboles cansados, sorprendidos zarzales junto al río, aferraos a vuestras raices, no desprenderos de ellas antes de que os arrase sin consuelo el torrente de odio que se acerca.

Llega el momento de repudiar el silencio, de competir con el fuego en la mañana fría, de poner un dique al agua envenenada. Llega el momento de tocar a rebato las campanas, de clamar, de gritar, de encresparse para que los ciegos vean $y$ los sordos oigan.

Adolfo Sánchez VázQuez, ELEGÍA A UNA TARDE DE JULIO, (FRAGMENTO) 


\section{Introducción}

Dentro del corpus bibliográfico del pensamiento estético de Adolfo Sánchez Vázquez se encuentra "recluido" en el olvido, por voluntad de su propio autor, el texto Conciencia y realidad en la obra de arte (1955), que fuera su tesis de recepción para la obtención del grado de Maestro en filosofía por parte de la UnAm. ${ }^{l}$ Diez años después, nuestro filósofo se verá envuelto en una serie de discusiones originadas por su libro Las ideas estéticas de Marx (1965), en el que sus tesis, aparentemente, no tienen nada que ver con las vertidas en el trabajo de grado ya señalado. No obstante, la mayoría de las polémicas desatadas en torno a Las ideas estéticas de Marx se suscitaron por su segunda parte "El destino del arte bajo el capitalismo" en donde nuestro autor desarrolla una de sus tesis más importantes: la hostilidad de la producción capitalista al arte. Basta recordar las réplicas de Ramón Xiráu y del poeta Luis Cardoza y Aragón, a las cuales el filósofo exiliado tuvo a bien contestar puntualmente (Vargas, 1995: 355-370). Al tener en cuenta su tesis de maestría las polémicas no se centran en esta segunda parte, sino que nos amplía una visión panorámica de la evolución de su pensamiento y nos da luces para entender los posicionamientos dejados en claro en la primera parte "En torno a las ideas estéticas de Marx y los problemas de una estética marxista".

El mismo filósofo dedica unas líneas para hablar sobre esta tesis en su texto La estética y la teoría del arte, en el que, además, sostiene

${ }^{1}$ Su examen se celebró el 9 de marzo de 1955. El jurado resolvió "aprobarlo por unanimidad magna cum laude". Dicho jurado lo conformaron: Dr. Samuel Ramos (presidente), Dr. Leopoldo Zea (primer vocal), Dr. Wenceslao Roces (segundo vocal), Mtro. Juan Hernández Luna (tercer vocal), Mtro. Eli de Gortari (secretario). Una copia de dicha acta se encuentra en Federico Álvarez (ed.), Adolfo Sánchez Vázquez. Los trabajos y los días (1995). 
que hay algunos puntos en donde no está de acuerdo y hay otros que son "rescatables":

Al problema del realismo se asociaba el de la ideología pues a la visión de la realidad -verdadera o falsa- se le hacía depender de la ideología que la inspiraba. [...]

La respuesta que daba entonces me sigue pareciendo hoy uno de los aspectos rescatables de la tesis. [...] O sea, como diré más tarde en otros trabajos, el contenido ideológico se da ya formado en la obra. [...]

El cambio que pocos años después se daría en mi pensamiento estético determinó mi decisión de no publicar la tesis -aunque ésta fue publicada, sin mi autorización, por la Universidad de San Salvador- (Sánchez Vázquez, 2009: 29-30).

No obstante, para entender mejor el giro crítico que nos ocupa, hace falta encontrar un artículo que el filósofo de la praxis dice haber escrito en el año de 1957 (dos años después de realizar su tesis) en el cual sostiene, como confirman diferentes escritos posteriores, que ya empezaba a criticar ese marxismo dogmático

En un ensayo posterior - de 1957- consagrado al arte que se consideraba propio de la nueva sociedad surgida de la Revolución rusa de 1917, el realismo seguía moviéndose por el mismo cause aunque yo trataba de darle, dentro de él, un carácter abierto frente a las deformaciones e interpretaciones estrechas y dogmáticas del “realismo socialista” (Sánchez Vázquez, 2009: 29-30).

Y en otro escrito vuelve a afirmar, aportando más datos, que

Pronto mis ideas en el campo de la estética y, por tanto, los principios que yo defendía en mi tesis, fueron quedándose atrás. Por 
esta razón, decidí no publicarla. A pesar de ello, en un ensayo que publiqué en 1957 en Nuestras Ideas, revista del PCE, si bien yo perseguía el intento de abrir nuevas brechas en la roca inconmovible de la estética soviética, no acababa por romper el marco teórico “ortodoxo” (Sánchez Vázquez, 2003: 36).

El estudio de este ensayo podría aportar más datos en la reconstrucción del proceso de cambio a su marxismo crítico. Por tales motivos, atender su importancia y vigencia en el pensamiento de su autor es una de las necesidades de este trabajo, la cual apunta a sistematizar, en la medida de lo posible, el pensamiento de Sánchez Vázquez. Si el autor trató de olvidar su tesis negando siempre su publicación, ${ }^{2}$ ahora no podemos negar que varias de sus tesis principales posteriores se encuentran, de alguna manera, en esta tesis de grado y otras más nunca son negadas sino transformadas en su pensamiento.

Releer Las ideas estéticas de Marx a la luz de Conciencia y realidad en la obra de arte nos hace pensar en la evolución del pensamiento crítico de Sánchez Vázquez. Ver hasta qué punto evolucionó, qué ideas transformó y cuáles no en su pensamiento estético, es la intención de esta investigación.

Por último, este ejercicio nos hace pasar del terreno anecdótico al documentado, acerca del pensamiento marxista ortodoxo de Sánchez Vázquez, el cual asumió de manera casi autodidacta. Para ello, no se cuenta con gran cantidad de documentos directos, a excepción de sus poemas y de lo dicho por él mismo en distintas con-

${ }^{2}$ Es necesario recordar que en San Salvador, El Salvador, publicaron Conciencia y realidad en la obra de arte, justo en el año en que se publicó Las ideas estéticas de Marx, 1965. Esta publicación no fue con la autorización del autor y, según lo dice uno de los hijos de Sánchez Vázquez, fue un alumno del filósofo quien lo publicó. 
ferencias. ${ }^{3}$ Normalmente, se asume una idea, de manera general, de lo que implica un marxismo ortodoxo en Sánchez Vázquez. Si bien al hacer esto no se yerra, no se deja de estar en el plano anecdótico. Estudiar, pues, esta tesis nos permite conocer los planteamientos ortodoxos que preocupaban a Sánchez Vázquez, cómo los formulaba y hasta dónde alcanzó la autocrítica en su propio pensamiento. Sirva esta investigación como un primer acercamiento a algunos temas que se consideran centrales.

\section{Estética como ciencia}

Sánchez Vázquez habla de conciencia y realidad para poder explicar la actividad artística dentro de las sociedades. No sólo eso sino que también pretende, desde estos conceptos, explicar y defender la llamada estética materialista. Si podemos afirmar en qué corriente filosófica estética se encuentra nuestro filósofo antes de Las ideas estéticas de Marx es en la estética materialista, la cual sostuvo el realismo socialista, con la que después no estaría de acuerdo y se dedicaría a desmontar.

Para tal cometido, nuestro autor empieza defendiendo a la estética como una ciencia. Es de notar que la primer cita con la que fundamenta su tesis es de Stalin, y la usa para señalar que, para que la estética se entienda como ciencia, tiene que estudiar las leyes objetivas de los fenómenos, pues estas leyes rigen las dinámicas naturales y sociales; por tanto, el estudio y entendimiento de éstas, origina las disciplinas científicas. Ahora bien, recurre a Stalin para definir lo que es una ley como "el reflejo de procesos objetivos que se operan independientemente de la voluntad humana". No

${ }^{3}$ Para una lectura de su poesía con un estudio crítico de ellas véase Adolfo Sánchez Vázquez, Poesía (2005). Sobre las conferencias referidas véase: Adolfo Sánchez Vázquez, Una trayectoria intelectual comprometida (2006). 
sólo pasa por un dato curioso que Sánchez Vázquez cite a Stalin, la importancia es fundamental ya que desde esta postura, el joven filósofo va a entender y fundamentar todo su pensamiento ortodoxo. Una ley objetiva es el Partido, aquella que señala el espíritu tendencioso de la obra de arte, la cual escapa de la voluntad del hombre. Leer al filósofo marxista crítico bajo el dogma soviético resulta un ejercicio extraño.

Hasta ahora Sánchez Vázquez ha tratado de explicar la estética como ciencia con la finalidad de entenderla bajo la ley objetiva del Partido, la cual es imposible modificar y mucho menos cancelar (Sánchez Vázquez, 1955: 4). No obstante, es necesario aclarar otro asunto: el autor de Filosofía de la praxis salva del normativismo a la ciencia estética, pues asegura que lo que pretende la estética como ciencia es descubrir leyes ya dadas, no imponer normas creadas por ella. Destacar esta idea es importante porque Sánchez Vázquez siempre estará en contra del normativismo en su pensamiento crítico. Idea que surge en esta tesis aunque con matices distintos. En este caso, aboga por el objetivismo de la ley aduciendo que el normativismo implica la introducción del subjetivismo y del voluntarismo en el arte (Cf. Sánchez Vázquez, 1955: 4) En este caso, normativizar sería ir contra las leyes objetivas que rigen a los fenómenos, sería alterar la dinámica ya establecida por dichas leyes.

Sin embargo, en el primer ensayo que aparece en Las ideas estéticas de Marx titulado "Vicisitudes de las ideas estéticas de Marx", escrito en 1965, al referirse al realismo socialista dirá:

[...] la interpretación del principio leninista del espíritu de partido de la obra de arte en una forma administrativa, orgánica, limitó en muchos casos la libertad de creación [...] Todo esto determinó que la estética del realismo socialista, al dejar de postular un trato infinitamente diverso con lo real, estableciera normas y fijara modelos, convirtiéndose así en una estética normativa, incompatible 
con las posiciones marxistas en que pretendía fundarse (Sánchez Vázquez, 2005: 16-17).

Ya se dijo que Sánchez Vázquez pretendió ir contra el normativismo científico, ahora para desprenderse ideológicamente del realismo socialista lo juzga como tal. Si antes lo defendía, por pensar que no era normativo, ahora está en contra de él por pensarlo así. Se puede apreciar entonces que su pensamiento no cambia, pues su preocupación es la misma (ir contra el normativismo), lo que cambia es el modo de operar, el modo de justificar qué es y qué no es normativo.

¿Cómo es posible este cambio en su pensamiento? El autor comenta que la lectura de los Manuscritos del 44 es la clave para pensar de nuevo el trabajo artístico. Con esto, se pretende desprender del realismo socialista; el siguiente paso es regresar a las ideas de Marx sobre el tema de la estética. Con ello, puede refundar una posible "estética marxista". Todavía en el prólogo a su antología de Estética y Marxismo (1970), existe la intención de brindar los principios que determinarían lo que sería una estética marxista (Cf. Sánchez Vázquez, 1970: 22-27). Sus objetivos cambian al especificar, en una conferencia titulada "La Estética y la Teoría del Arte", que no pretende realizar una estética marxista sino una "estética a secas, sin adjetivos" (Sánchez Vázquez, 2006: 54). Aunque estas anotaciones rebasan los objetivos de este trabajo, ciertamente es importante tenerlas en cuenta.

$\mathrm{Al}$ repelar el normativismo de la estética pensada como ciencia, Sánchez Vázquez hará otra precisión importante en Invitación a la Estética (1992), en la que asegura que "hoy la Estética más que una ciencia constituida es más bien un proyecto de ciencia que avanza lenta y penosamente en su realización, a partir de ciertos supuestos filosóficos [...] y con la ayuda de diversas ciencias sociales" (Sánchez Vázquez, 1992: 34). Si en 1955 decía que la estética es una 
ciencia ya determinada por las leyes objetivas que la rigen, en 1992 asegura que es apenas un proyecto de ciencia guiada, ya no por estas leyes sino por supuestos filosóficos como lo son el hombre, la sociedad, la historia, el conocimiento y por diversas ciencias sociales. Evidentemente su concepción ha cambiado. Aquí sí podemos ver un cambio en los medios y fines de su pensamiento. Si en Las ideas estéticas de Marx no habla de la estética como una ciencia es porque apenas está asentando las ideas que fundarán esa ciencia a la que quiere llegar, propiamente una estética marxista: "En principio, los estéticos marxistas de todos los países pueden y deben contribuir al esclarecimiento y fecundación de las ideas estéticas de Marx y, sobre su base [...], construir los pilares de una verdadera estética marxista” (Sánchez Vázquez, 2005: 18).

\section{Teoría y práctica}

La estética, como ciencia que obedece las leyes objetivas determinantes, sino se nutre de normas lo tiene que hacer de la misma práctica artística. Sánchez Vázquez entiende que "la ciencia de las leyes que rigen el desarrollo artístico, como todo verdadero conocimiento, ha de estar vinculado a la práctica” (Sánchez Vázquez, 1955: 8). Esta necesidad surge del peligro de caer en un objetivismo radical propiciado por el seguimiento de las leyes objetivas y, de esta manera, no llegar al error que nuestro autor ve en el idealismo de desvincular la teoría con la práctica (Sánchez Vázquez, 1955: 10). Con esto, Sánchez Vázquez pretende estar en un punto intermedio del objetivismo y el subjetivismo.

La práctica artística la entiende como trabajo, es decir, como proceso en el cual una materia determinada es transformada por el artista. La obra de arte es trabajo, proceso consciente de transformación de la naturaleza. Este trabajo artístico expresa la relación que tiene el hombre con la naturaleza, pero también, en el produc- 
to artístico se expresa la relación del hombre en sus relaciones con los demás. Éste es el ámbito social del proceso de creación artística.

Estas ideas no son extrañas al pensamiento de Sánchez Vázquez, de hecho podemos ver en ellas una prefiguración de su artículo "Ideas estéticas en los Manuscritos económico-filosóficos de Marx" publicado en Diánoia en 1961, el cual después incluiría con una modificación casi total en Las ideas estéticas de Marx, cuatro años después, con un título diferente: "Las ideas de Marx sobre la fuente y naturaleza de lo estético". En cambio, el matiz al que nos referimos es distinto y elemental.

Al filósofo marxista le interesa vincular adecuadamente su anunciado objetivismo con pretensiones científicas con la realidad eficiente, no solamente para tratar de solucionar la problemática que ve en el idealismo sino, principalmente, para ajustar esta ciencia estética a la nueva realidad social que es el socialismo. La explicación de Sánchez Vázquez es la siguiente:

La teoría del arte no puede desvincularse, en nuestro tiempo, de la actividad concreta, real. Por ello, tiene que encararse con una nueva manifestación artística, el realismo socialista, el realismo que corresponde a una nueva realidad social. La estética ha de contar con las obras creadas siguiendo los principios de esta nueva orientación artística (Sánchez Vázquez, 1955: 9).

Así, la nueva realidad social, que obedece a las determinaciones históricas y sociales, tiene que estar conforme con las leyes objetivas que rigen la ciencia de la estética. De esta manera, teoría y práctica están unidas, en una dinámica en la que la teoría, atendiendo la nueva realidad social, fecunda a la práctica artística. Este esfuerzo teórico es el que pretende realizar la estética materialista fincada en la extinta Unión Soviética y justamente es el objetivo central de su tesis de grado: "El presente trabajo pretende contri- 
buir, aunque sea modestamente, a que el arte, que aspira a expresar la nueva realidad social, acorte la distancia que le separa de ella" (Sánchez Vázquez, 1955: 11)

Este tema de teoría y práctica será fundamental en su pensamiento posterior y tendrá un punto álgido en su Filosofía de la praxis, trabajado y defendido justamente en su tesis de doctorado. Aquí se pueden encontrar algunos intereses rectores de su pensamiento, principalmente la idea preclara de la praxis. Ciertamente, ahora nos sirve para explicar que la conciencia a la que se refiere en el título de su tesis es la del artista, la cual tiene que estar en concordancia con la realidad, que es precisamente la nueva realidad social, es decir, el socialismo realmente existente. Para saber si la concordancia es efectiva existe la ciencia de la estética, la cual, por medio de sus métodos científicos, descubre las leyes que determinan la práctica de los artistas.

\section{Música, marxismo ortodoxo y marxismo crítico}

Salvo algunas menciones y pequeñas explicaciones, Sánchez Vázquez no habla de música. De hecho, podríamos decir que su tesis de maestría es el único texto donde aborda el tema ampliamente. Pero esto es una hipérbole, pues en realidad el apartado "La imagen musical" del capítulo III "La imagen artística y la realidad" solamente ocupa tres hojas y media de la tesis. No obstante, cuenta como el escrito más amplio sobre el tema en sus trabajos, y por esto merece una atención especial.

Sánchez Vázquez asume que, tanto en la poesía como la pintura, se pone en juego la imagen, la cual sistemáticamente se puede pensar en una estructura de tres partes: sensible, lógica (representativa u objetiva) y afectiva, es así que "el material sensible, la realidad representada, los conceptos, la densidad afectiva de la obra de arte, aparecen fundidos en un producto único, singular, irrepe- 
tible" (Sánchez Vázquez, 1955: 59). Lo que le interesa a nuestro autor es estudiar la imagen para poder explicar el movimiento de lo general a lo particular, es decir, el movimiento de los conceptos a la imagen, propiamente la imagen artística. Es así como un olmo viejo no es lo mismo para un científico que para un artista ya que en este último median sus sentimientos y su manera de concretarlo en una imagen.

En la música se suprime la representación de la realidad exterior, es decir que se niega uno de los aspectos sensibles de la imagen, el representativo u objetivo. Sánchez Vázquez afirma que: "lo sensible en la música no se carga de significaciones objetivas, de representaciones, sino que es dotado, directamente, de una tensión afectiva. Esta tensión hace que la música se convierta también en un lenguaje común, a pesar de que falta el puente de la representación objetiva" (Sánchez Vázquez, 1955: 61-62). La significación no se pierde a pesar de no tener representación objetiva, ya que dicha significación es aportada por la tensión afectiva.

A pesar de la tensión afectiva, en la obra musical se impregnan las ideas dominantes de cada época y estas ideas aparecen, fundidas, en las formas o imágenes musicales. La tensión afectiva no excluye la utilización de ideas y conceptos para la realización de una obra musical, es, más bien, en el producto en donde la representación objetiva de la imagen desaparece. La pura tensión afectiva terminaría en un idealismo al cual nuestro autor repele afirmando que, de caer en él, se cometería el error de separar la realidad histórico-social de la conciencia del artista. Al fundir las ideas con lo afectivo, es decir, con los sentimientos, éstas los dirigen, es así como el filósofo de la praxis fundamenta el contenido ideológico en la obra de arte musical, y como Sánchez Vázquez afirma que: "el contenido ideológico de una obra de arte será tanto más profundo cuanto más concreta sea la encarnación de la idea en la imagen" (1955: 64). El dar cabida al contenido ideológico, 
como ya se vio, es fundamental para la relación entre conciencia y realidad. Es importante decir que la ideología en la obra es un tema que Sánchez Vázquez seguirá desarrollando de forma similar a lo que plantea aquí. ${ }^{4}$

El interés por el tema musical nace por el interés de estudiar la imagen artística en relación con la realidad. Si bien el tema musical no es recurrente en nuestro autor como lo son los temas de literatura y pintura, sí podemos seńalar que este apartado reviste una importancia a la luz de su pensamiento posterior, pues interesa la relación de la realidad y la imagen artística, en este caso musical.

Otra mención importante del tema musical en la obra de Sánchez Vázquez se encuentra en la quinta conferencia De la Estética de la Recepción a una estética de la participación (2005), donde habla sobre "La intervención del receptor en nuevas experiencias artísticas del siglo xx y, en particular, en las asociadas con las últimas tecnologías". En este texto se basa en el concepto de "obra abierta" de Umberto Eco para afirmar que una recepción activa por parte del público afecta la realidad sensible y material de la obra de arte. En este caso hablará de John Cage, Stockhausen, Luciano Berio, Henri Pousseur y Pierre Boulez (Cf. Sánchez Vázquez, 2007: 81) para referirse a la posibilidad de modificar y afectar materialmente -en este caso en el sonido y no sólo en los significados e ideas- la realidad. Así, justifica lo contrario de lo sostenido en su tesis de maestría. Con esto podemos darnos cuenta que Sánchez Vázquez utiliza el tema de la música como un medio para explicar sus posturas estéticas. Y aunque sólo lo utiliza como ejemplo, el apartado de su tesis es el único dedicado enteramente a la música.

${ }^{4}$ Baste referirnos por ahora al trabajo "Literatura, ideología y realismo” (1996). 


\section{Estética materialista y vanguardias}

Todo aquel que no cumpla con las leyes objetivas es porque no ha entendido la realidad en la que vive. Por esto, nuestro autor reclama a las vanguardias y al arte primitivo

La realidad puede ser, por el contrario, traicionada y aparecer invertida, deformada, como acontece en las tendencias antirrealistas del arte primitivo, o en los movimientos artísticos que, arrancando del impresionismo de fines del siglo XIx, llegan hasta nuestros días, pasando por el cubismo, surrealismo, arte abstracto, etc.

Pero, en uno u otro camino, el contenido objetivo de la obra de arte es la realidad misma, aunque ésta se refleje adecuadamente en Velázquez y falsa, monstruosamente, en un Dalí (1955: 13-14).

Aunque al arte rupestre como a las vanguardias de finales del siglo XIX y principios del xx las ve como formas degeneradas de la práctica artística no niega que sean arte, que sean productos artísticos. Lo que afirma Sánchez Vázquez es que son productos artísticos deformes o que deforman la realidad. En este punto podemos apreciar lo que parecería una contradicción en su tesis, ya que al afirmar que esta deformación -aunque posible- es errónea, en el capítulo IV afirma que

el arte, en cuanto refleja la realidad, ha de pasar también de la percepción sensible al pensamiento abstracto, de lo particular a lo general [...] El arte se alza desde lo inmediato para volver a él, de nuevo, tras de haber alcanzado lo general. No está, por tanto, libre de la generalización, ya que no se limita a copiar los detalles, a registrar la realidad pasivamente (Sánchez Vázquez, 1955: 69-70). 
El realismo, por ser reflejo de la realidad, no es pasivo de ella y no refleja una realidad objetiva sino una realidad interpretada por el artista. De esta manera da cabida a las vanguardias y su interpretación de la realidad, aunque es cierto que Sánchez Vázquez afirma que "la subjetividad del artista no puede romper con la objetividad de lo real" (1955: 71), descalificando a las vanguardias. Lo que no explica es cómo es posible que un artista rompa totalmente con la realidad. Si ya antes dijo que las vanguardias deforman la realidad, no quiere decir que rompan totalmente con su objetividad. Aunque la objetividad de la realidad es lo que importa, esto nunca se realiza como tal, ya que "la realidad requiere, por tanto, ser incorporada a la obra de arte, pero lo que se incorpora no es la realidad 'objetiva', sino una realidad interpretada, enjuiciada, valorada por el artista” (1955: 72). Para Sánchez Vázquez es claro porque la objetividad de la realidad no es otra más que el socialismo realmente existente.

Asimismo, la importancia que reviste ahora el tema de la estética materialista en relación con las vanguardias es más importante que revisar las consistencias y contradicciones en dicha tesis. Esto es así porque Sánchez Vázquez se está cerrando al dogmatismo del realismo socialista de una manera abierta y sin tapujos. Nuestro filósofo es claro y contundente. Entonces no hay otro camino para el trabajo artístico que seguir los lineamientos del realismo socialista, ya que éste obedece las leyes objetivas, las cuales determinan la dinámica de la nueva sociedad, la cual requiere un arte que esté a la altura de las leyes que la rigen. Lo que Sánchez Vázquez está haciendo no es más que subsumir el trabajo artístico al ámbito político, y aunque esto no es su conclusión original sino del realismo socialista, el filósofo sólo sigue al pie de la letra los lineamientos que explica desde los conceptos de conciencia y realidad.

Esta lectura en la que se juzga el pensamiento de nuestro autor como un pensamiento cerrado y dogmático es consecuencia de la 
distancia con la que se estudia. Sánchez Vázquez parece tener toda la confianza puesta en el realismo socialista, y lo hace de manera aparentemente justificada, pues en esta propuesta percibe un mejor futuro para la actividad artística. De lo contrario, es decir, al no seguir el realismo:

El arte perderá también toda significación como medio de transformación de la conciencia misma, y con ello de la realidad. Si, por el contrario, el arte nos entrega aspectos profundos, esenciales de la realidad, podrá ser instrumento de comunicación, y con ello, influir sobre los demás, contribuyendo así a transformar la propia realidad. El arte será medio de liberación y enriquecimiento del ser humano (Sánchez Vázquez, 1955: 14).

Una vez más podemos observar cómo Sánchez Vázquez no cambia en sus fines sino en sus medios, ya que siempre pensará que el arte es liberación y enriquecimiento del ser humano aunque lo haga de distintas formas. De hecho, justamente para mantener su postura es necesario que cambie de pensamiento pues se dará cuenta que el dogmatismo socialista no es la mejor opción para pensar en liberación y enriquecimiento; esto es, para mantener su pensamiento tiene que cambiar los fundamentos que lo sostienen. El cambio afecta su base pero no sus fines. Se puede encontrar la radicalidad del pensamiento crítico de Sánchez Vázquez en la valentía de cambiar los fundamentos de su pensamiento y no sus fines y seguir siendo fiel al pensamiento marxista.

Una lectura sugerida que evidencia lo anterior se encuentra en el prólogo a la primera edición de Las ideas estéticas de Marx, que parece ser un manifiesto en contra de Conciencia y realidad en la obra de arte. Este preámbulo es una declaratoria sintética de su cambio de visión del marxismo y es la pauta para todo su pensamiento crítico posterior. Al regresar a Marx para postular, en lo posterior, 
una estética marxista pretende desligarse y, más aún, negar el valor de verdad absoluta a la estética materialista. Esto queda claro en el segundo párrafo, donde incluye el urgente tema del arte moderno, al cual anteriormente ha calificado de monstruoso

Los problemas estéticos suscitan cada vez mayor interés entre los investigadores marxistas. Ello responde a diversos motivos. Uno es la necesidad general de superar en este campo como en otros las concepciones dogmáticas y sectarias que determinaron en los ańos de deformaciones stalinianas -teóricas y prácticas- del marxismo. [...] Independientemente del lugar que le concedamos desde un punto de vista histórico-social, como parte de una supraestructura ideológica, y del valor que le atribuyamos en un plano estético, el arte moderno es un hecho rico, complejo y contradictorio al que no podemos acercarnos con los criterios esquemáticos y simplistas que dominaron en la crítica marxista hasta hace unos años (Sánchez Vázquez, 2005: 1)

Es claro el cambio de lugar desde el cual hace su reflexión filosófica. No podemos leer esto más que como un manifiesto en el cual el filósofo de la praxis nos anuncia su cambio de postura, pues no contento con lo ya dicho, y después de explicar la importancia de regresar a la raíz de las ideas estéticas de Marx para desarrollarlas, todavía arremete diciendo que "Al descubrimiento y examen de esas raíces, por un lado, y a su aprovechamiento, por otro, teniendo como fondo la experiencia artística en su conjunto, y la contemporánea, de modo especial, están consagrados los ensayos que forman el presente volumen" (Sánchez Vázquez, 2005: 1-2)

Asimismo, el prólogo a la primera edición puede ser el puente que liga y, a la vez, diferencia las ideas vertidas en su tesis de maestría y su posterior trabajo crítico. Cabe acotar que este movimiento no es propio u original de Sánchez Vázquez. Su originalidad 
no está en el paso del marxismo dogmático a un cierto marxismo crítico, pues este paso fue un paso a nivel mundial, era un paso necesario si se quería seguir reflexionando en el marxismo, era un "renovarse o morir". Nuestro autor logró dar este paso desarrollando a la vez su pensamiento. La originalidad está en la autocrítica y en el desarrollo de sus ideas y de todo su pensamiento posterior a partir de este ejercicio.

\section{Conclusiones}

Por medio de este ejercicio de análisis y comparación podemos ver que las discusiones ya no se centran en la segunda parte de Las ideas estéticas de Marx sino que se desarrolla un giro notorio de interés por la primera parte que apenas fue discutida. ¿A qué se debe esto? Revisar Las ideas estéticas de Marx a la luz de Conciencia y realidad en la obra de arte nos hace atender la fundamentación del pensamiento de Sánchez Vázquez; no solamente eso, sino en los cambios en su fundamentación, en su evolución y renovación; ya que, según este estudio, este cambio se encuentra explicado en la primera parte.

Se puede apreciar que el pensamiento de Sánchez Vázquez más que cambiar pretende ser fiel a sus principios de antinormativismo: pensar la estética como ciencia, la actividad artística como trabajo creador y el trabajo como determinación de las relaciones sociales del hombre con la naturaleza y la sociedad. Esto obliga al filósofo de la praxis a tener que cambiar sus fundamentos con la intención de renovarse para ser congruente. Esta refundamentación implica cambios como el del enjuiciamiento al arte moderno y contemporáneo, el cual le dará mucha fuerza a su posterior pensamiento crítico.

Si se tiene que afirmar que el pensamiento de Sánchez Vázquez es crítico, tendríamos que decir que primero es crítico de sí mismo 
y es valiente al dar el paso en rectificarse, también es crítico al no sólo rectificarse sino en denunciar los errores de aquello a lo que antes pertenecía. Sin embargo, su crítica no pretende más que una refundación de cierto marxismo, un marxismo de la praxis, el cual lo que quiere es reafirmarse. En este caso la crítica tiene la función de reafirmación, en este sentido, de empezar de nuevo, de no dar todo por terminado, de reavivar la esperanza. ¿Se puede hablar de necedad? Tal vez sí, pero esta respuesta se tendrá que justificar con la revisión total de su pensamiento estético, más aún, de su pensamiento en general.

La lectura de Conciencia y realidad en la obra de arte supera los límites temáticos que se encuentran en Las ideas estéticas de Marx, por eso aquí se vislumbraron discusiones más allá de estos límites, corriendo el riesgo de desbordar los objetivos del presente. Lo que se pretendía era mostrar en qué medida este texto influye en el estudio del pensamiento de este filósofo. Por ahora la intuición es que su importancia alcanza discusiones con Filosofía de la Praxis en relación al concepto de trabajo. La llamamos intuición porque lo certero es que la influencia de Conciencia y realidad en la obra de arte en Las ideas estéticas de Marx es mayúscula y tenerla en cuenta para el estudio del pensamiento de su autor es imprescindible.

Finalmente, falta acotar otros temas que, aunque también son importantes, por ahora no se presentaron, ya que lo que interesaba era fundamentar la influencia de la tesis de posgrado con el texto en cuestión. Entre estos temas está el de la dialéctica entre tradición y la creación en los dos textos. Resulta curioso que tanto la tesis de grado como Las ideas estéticas de Marx terminen con este tema sobre las tradiciones, el arte popular y la creación vanguardista. No obstante, este primer acercamiento a su tesis de posgrado arroja luces importantes, sobre todo para el estudio de su pensamiento estético. 


\section{Bibliografía}

Álvarez, Federico (ed.), 1995, Adolfo Sánchez Vázquez. Los trabajos $y$ los días, Universidad Nacional Autónoma de México, México. Sánchez Vázquez, Adolfo, 1955, Conciencia y realidad en la obra de arte, Tesis, Universidad Nacional Autónoma de México, México. México.

(comp.), 1970, Estética y marxismo, t. I, Ediciones Era,

, 1992, Invitación a la estética, Grijalbo, México.

, 1996, "Literatura, ideología y realismo", en Cuestiones estéticas y artísticas contemporáneas, Fondo de Cultura Económica, México, pp. 82-94.

, 2005, Las ideas estéticas de Marx, Ricardo Valdés (ed.), Federico Álvarez (pról.), Siglo XXI, México.

, 2005, Poesía, María Dolores Gutiérrez (pról.), Adolfo Castañón (epílogo), Centro Cultural de la Generación del 27, Fondo de Cultura Económica, México.

, 2006, Una Trayectoria intelectual comprometida, Universidad Nacional Autónoma de México, México.

,2007, De la Estética de la Recepción a la estética de la participación, Ocelote y Luis Cortés Bargalló (eds.), Universidad Nacional Autónoma de México, México.

Vargas Lozano, Gabriel, 1995, En torno a la obra de Adolfo Sánchez Vázquez (Filosofía, Ética, Estética y Política), Juan Carlos H. Vera (ed.), Universidad Nacional Autónoma de México, México. 